\title{
Inaugural editorial: an honour and a great challenge
}

\author{
S. S. lyengar \\ School of Computing and Information Sciences, Florida International University, Miami 33199, FL, USA. \\ SW 8th St, Miami 33199, FL, USA. E-mail: iyengar@cs.fiu.edu \\ How to cite this article: Iyengar SS. Inaugural editorial: an honour and a great challenge. J Surveill Secur Saf 2021;2:162-3. \\ https://dx.doi.org/10.20517/jsss.2021.15 \\ Received: 27 Sep 2021 Accepted: 27 Sep 2021 Published: 31 Dec 2021 \\ Academic Editor: S. S. lyengar Copy Editor: Yue-Yue Zhang Production Editor: Yue-Yue Zhang
}

Correspondence to: Prof. S. S. Iyengar, School of Computing and Information Sciences, Florida International University, 11200

The successes of a journal can only be achieved through the efforts of many. I cannot tell you that how sharp my passion of being the Editor-In-Chief of this new journal and my first reaction that it is possible to make this journal a great one to knowledge dissemination in this area of Surveillance, Security and Safety of information science, cyber, machine learning, sensor, emerging technologies, and other systems and build real and enduring value to researches and practitioners around the world.

I have long believed that the journal cannot succeed unless our quality succeeds. This is particularly true in research journal's role as a centre of innovation, enterprise creativity and transition to technology.

The editorial board members of this journal under my leadership will develop an advance agenda to fulfil the research mission in the context of signatures of excellence while continuing to build the areas that will give us in other dimensions the quality we expect researches and readers of this Surveillance, Security and Safety of information science, cyber, machine learning, sensor, emerging technologies, and other systems.

Living up to the honour of our making the best journal in this area is a challenge to which we will continue to strive to rise thorough the exemplary efforts of so many members of our marvellous research community.

We welcome contributions that can demonstrate near-term practical usefulness, particularly contributions that take a multidisciplinary/convergent approach because many real world problems are complex in 
nature.

I close this message by inviting everyone to submit their exciting research to Journal of Surveillance, Security and Safety (JSSS). All papers receiving a high degree of enthusiasm in the peer-review process will find a home in JSSS. Therefore, we are committed to publishing all discoveries, methods, resources, and reviews that significantly advance the field of Surveillance, Security and Safety of information science, cyber, machine learning, sensor, emerging technologies, and other systems and its applications.

Once again, I welcome you to this journal - your journal! With your support as authors, reviewers, and editors, I see very bright prospects for JSSS to serve science and the scientific community even better in the future. Ultimately, we will improve more lives and, consequently, our communities.

We hope to hear from you soon, and we welcome your feedback!

Thank you. We hope you will find JSSS informative.

\section{DECLARATIONS}

Authors' contributions

The author contributed solely to the article.

\section{Availability of data and materials}

Not applicable.

\section{Financial support and sponsorship}

The author has not declared a specific grant for this editorial from any funding agency in the public, commercial, or not-for-profit sectors.

\section{Conflicts of interest}

The author declared that there are no conflicts of interest.

\section{Ethical approval and consent to participate}

Not applicable.

\section{Consent for publication}

Not applicable.

\section{Copyright}

(c) The Author(s) 2021. 